\title{
El indianismo en la América hispánica. Una nebulosa política equívoca ${ }^{1}$
}

\author{
Jean-Pierre Lavaud ${ }^{2}$ y Françoise Lestage ${ }^{3}$
}

Durante la colonización española, el término "indio" designaba a los habitantes precolombinos de las Américas que pagaban el tributo. En la actualidad, demógrafos y empadronadores contabilizan a los indios sobre la base de los grupos étnicos (maya, mapuche, quechua) y a marcadores culturales fluctuantes. Paralelamente, en los escenarios políticos nacionales e internacionales, los indígenas son cada vez más numerosos. En concordancia con las preocupaciones contemporáneas, hablan de clase, cultura, ecología o desarrollo sostenible. Utilizan tecnologías de punta, en particular los medios de comunicación electrónicos. La mayoría vive, trabaja y se moviliza en colaboración con las ONGs, asociaciones variadas, y "mestizos" de todos los orígenes geográficos y nacionales.

El resurgimiento, o más bien la redefinición de esta indianidad (que podemos definir como la particularidad de quienes se consideran y son considerados como indígenas) no puede ser disociado de la difusión de la ideología indianista, considerada como un elogio a y un énfasis en la indianidad, pero que es ante todo un movimiento de adhesión y apoyo a las organizaciones políticas portadoras de esta corriente y a las manifestaciones que provoca. La atención prestada a los indígenas es tal que ha implicado -hace una década-cambios en los trabajos de las ciencias humanas sobre este tema, cada vez menos orientados hacia la cultura y cada vez más hacia las luchas políticas (Van Cott, 2003). Estas luchas suscitan el interés creciente de un público cada vez más amplio, que toma partido por los indígenas, a menudo impulsado por algunas figuras famosas o por los escritos de periodistas y científicos, en los cuales se denuncian los abusos y las injusticias que sufren las poblaciones calificadas como indígenas.

Pero la etiqueta "indígena" es también un recurso para una multitud de grupos, en su mayoría políticos, pues les permite acceder al apoyo de organismos internacionales o de empresas, así como al respaldo político de intelectuales, líderes sociales y políticos de los países del "Norte". "Fabricar al indio" constituye,

1 Este artículo ha sido publicado en la revista Esprit (París) en enero de 2006. La versión inicial ha sido modificada en función a los comentarios y sugerencias de André Quesnel (IRD) y de Stéphanie Alenda (Universidad de Chile), a quienes agradecemos por su atenta lectura. Traducción: Enrique Herrera Sarmiento, Ainhoa de Federico de la Rúa, Emmanuelle Barozet.

2 Profesor titular de sociología, Universidad de Lille 1, CLERSÉ. Correo electrónico: Jean-Pierre. Lavaud@univ-lillel.fr

3 Profesora titular de sociología, Universidad de Paris 7, URMIS. Correo electrónico: francoise. lestage@univ-paris-diderot.fr 
por tanto, una apuesta fundamental. Veremos que esa ostentación de la indianidad no corresponde a una voluntad igualitaria, ya que deja de lado categorías sociales definidas en términos de explotación, lo que produce una ambigüedad con la que juegan los sectores dominantes. Además, favorece la ascensión social rápida, personal y familiar, de un conjunto de líderes que recogen el beneficio de sus contactos con las agencias occidentales, lo cual abre nuevas desigualdades en los grupos en cuestión. El éxito del indianismo tampoco puede ser asimilado a un movimiento de democratización, ya que se apropia de movimientos políticos muy distintos, desde los más abiertos hasta los más cerrados.

\section{El proceso de emergencia de los indianismos}

Parece que actualmente, el análisis del florecimiento de los indianismos -de todo tipo- está vinculado a dos temas: por una parte, a las democratizaciones de los años noventa y sus insuficiencias, o sus lógicas individualistas o individualizantes; y, por otra, a la mundialización, en el sentido de la extensión de formas neoliberales salvajes, las que estarían individualizando y rompiendo los vínculos sociales. De hecho, cabe situar los indianismos del presente en una ola más antigua: la ola de la "venganza histórica de los particularismos", según la expresión del poeta y ensayista mexicano Octavio Paz (1985: 121). Se trata de una esfera de influencia histórica no sólo latinoamericana o americana, sino mundial, que se construye en el contexto de la globalización económica, pero que no es directamente explicable por ella. En realidad, los etnicismos locales no existirían sin una serie de evoluciones políticas, sociales e ideológicas continentales previas, en particular el indigenismo -corriente de defensa de las poblaciones autóctonas que se remonta al principio de la colonización-; el despertar indígena en los Estados Unidos; y una muy amplia red de apoyos intelectuales y materiales internacionales.

\section{DEL INDIGENISMO AL INDIANISMO}

El indianismo actual es, hasta cierto punto, el heredero del indigenismo, del cual extrae sus argumentos. Vieja corriente de defensa de las poblaciones autóctonas, el indigenismo se transformó en una ideología apoyada por algunas organizaciones, y, luego, por algunos Estados, entre los años veinte y setenta. El caso más emblemático fue México, donde algunos miembros de los gobiernos que se sucedieron durante la primera parte del siglo xx, así como antropólogos y escritores, vieron en la interacción de las culturas indígenas y europeas -consideradas como iguales- la aparición de una cultura nacional. Se postuló al respecto que las contribuciones occidentales debían modificar los aspectos deficientes de la vida indígena, sobre todo en lo científico y en lo técnico. Por su lado, las sociedades indígenas debían contribuir a crear y fortalecer los lazos comunitarios. Octavio 
Paz hizo incluso del Mexicano el descendiente de Cortés -el conquistador blanco- y de su amante -una princesa india- (Paz, 1992). En México y en otros países americanos, el indigenismo se articuló entonces con los nacionalismos, inscribiéndose el reconocimiento y la defensa de las culturas autóctonas en un movimiento general de reconstrucción a la vez integrador, progresista y antihispanista.

Se puede decir que el indianismo actual se nutre de las contribuciones de esta corriente, de las políticas y discursos que ha inspirado pero que, al mismo tiempo, se plantea como una ruptura u oposición frente a ella. Se puede ver que todas las expresiones artísticas a favor de los indígenas (literatura, pintura) contribuyeron en gran parte a rehabilitar y ennoblecer la historia y los rasgos de las culturas indígenas. Por su parte, las políticas sociales, educativas, o incluso económicas -particularmente en el caso de los países donde hubo reformas agrarias-, así como el acceso de la ciudadanía al sufragio universal, favorecieron la integración de las poblaciones rurales, antes mucho más dominadas y desamparadas. Paradójicamente, lo que está al origen de los discursos y de las movilizaciones diferencialistas actuales es, por una parte, la distancia persistente entre esas poblaciones y las poblaciones urbanas y, por otra, la apreciación que las primeras efectúan de tal diferencia y rechazo, facilitada tanto por su nueva integración social y cultural, como por la discriminación que siguen sufriendo en tanto indígenas. Es allí donde se encuentra el telón de fondo nacional común para el nacimiento del indianismo en los distintos países de la región.

Advirtamos que si bien la corriente indigenista ha sido asociada estrechamente con el nacionalismo de los Estados de la región, ésta también dio lugar a politicas locales específicas, inspiradas unas en otras, que tuvieron como consecuencia una red de instituciones comunes. Dan prueba de ello la organización de Congresos indigenistas internacionales y la instauración de institutos indígenas nacionales, promovidos por el Instituto Indigenista Interamericano. En México, el Instituto Nacional Indigenista, creado en 1948, fue ante todo una agencia para la aplicación de políticas de desarrollo, destinadas a integrar a las poblaciones indígenas, más que a construir un discurso sobre lo Indio. Dicho instituto desapareció en 2003 y fue reemplazado por un organismo cuyo nombre sugiere un proyecto más acorde con la actual ideología indianista: la Comisión Nacional para el Desarrollo del Pueblo Indigena (CONADEPI).

El Instituto Indigenista Interamericano rápidamente se convirtió en una agencia especializada de la Organización de los Estados Americanos (OEA) y muchos de sus programas de desarrollo destinados a las poblaciones locales fueron financiados por grandes agencias internacionales, como el Banco Mundial y el Banco Interamericano de Desarrollo. Fue el caso de la Misión Andina, que desarrolló programas en Bolivia y Ecuador en los años cincuenta y sesenta. Como lo destaca Henri Favre, "la política indigenista encuentra una consagración internacional con el Convenio 107 sobre las poblaciones indígenas, tribales y semitribales elaborado por la Organización Internacional del Trabajo (OIT) en 1957" (Favre, 1996: 91). Efectivamente, en un texto cuyo objetivo era lograr la igualdad de derechos entre poblaciones no autóctonas y autóctonas mediante la asimilación de estas últimas, 
la orT retomaba, por iniciativa propia y, en particular, de algunos de sus antropólogos influidos por la corriente culturalista anglosajona, los principios enunciados por el Congreso indigenista interamericano que tuvo lugar en Patzcuaro, México, en 1940. Se puede recalcar que el indigenismo conoció en su época una difusión tan internacional como el indianismo de hoy.

\section{El DESPERTAR INDIO EN AMÉRICA}

Históricamente, el despertar indio empieza con el período indigenista, antes de la ola de democratizaciones latinoamericanas. Las manifestaciones indianistas comienzan, en efecto, en los Estados Unidos en los años sesenta, con las luchas de los negros que pugnan por la obtención de derechos civiles. El American Indian Movement (AIM) fue creado, en 1968, en Minneapolis y muy rápidamente, sobrepasando los cuadros tribales, genera "un nacionalismo pan-indio" (Marienstras, 1980: 161). Luego, tiene lugar la toma del Bureau of Indian Affairs (BIA) en 1970, la ocupación de sus edificios en 1972, y los enfrentamientos en el Wounded Knee en 1973. Al mismo tiempo, el National Congress of American Indians y la Fraternité des Indiens du Canada realizan acciones buscando reconocimiento internacional.

En 1975, después del Congreso Indio de Port Alberni en Canadá, nace el Consejo Mundial del Pueblo Indigena (CMPI), al cual la ONU confiere un estatuto consultivo. En 1977, la primera conferencia internacional sobre este tema organizada por la ONU en Ginebra abre el camino a los indígenas de América. Entre el centenar de representantes que participan en ella, se encuentran los líderes de trece organizaciones de América Latina (Morin, Santana, 2002). Por último, en 1982, la Subcomisión de la ONU Contra las Medidas Discriminatorias y la Protección de las Minorías crea un grupo de trabajo sobre los pueblos autóctonos, con el fin de redactar "una declaración universal de los derechos de los pueblos indígenas" (Favre, 1996). Paralelamente, el parlamento Indio de América se reúne por primera vez en agosto de 1987. Los dos primeros encuentros mundiales de los pueblos indígenas, celebrados en Guatemala en 1993 y en México en 1994, y presididos por Rigoberta Menchu ${ }^{4}$, en representación de la Secretaría General de la ONU, marcaron otros dos hitos en la internacionalización de la lucha indianista. Éstas son, por supuesto, sólo algunas etapas de la ola indianista inicial, que se ampliará posteriormente.

Al mismo tiempo, en cada país centro y sudamericano donde existen grupos indígenas, se organizaron manifestaciones y se difundieron escritos que popularizan este despertar. Las organizaciones nacionales e internacionales nacientes se presentaron como las continuadoras de una lucha incesante, que se había llevado a cabo desde principios de la colonización. En 1964, en Ecuador, se creó la Fe-

4 Quiché guatemalteca, Premio Nobel de la paz en 1992. 
deración Shuar, que agrupa a parte de la población indígena de ese país. Luego, en 1980, siempre bajo el impulso del Shuar, nació la Confederación de Nacionalidades Indígenas de la Amazonia (CONFENAIE). En Bolivia, surgieron en 1971 los Kataristas al interior del sindicalismo campesino, tomando el nombre del jefe indio Tupak Katari; y, en 1981, nació la Central Indígena del Oriente Boliviano (CIDOB). Durante ese mismo período, específicamente en el año 1980, se creó en Perú la Asociación Interétnica de Desarrollo de la Selva Peruana (AIDESEP). Por su parte, en 1980, se fundó en Ollantaytambo El Consejo Indio de Sudamérica (CISA), con ocasión del primer Congreso indio que tuvo lugar en esta parte del continente. Más al norte, en Guatemala, distintas organizaciones creadas al final de los años ochenta se agruparon en 1990, en el Consejo de Organizaciones Mayas de Guatemala (COMG). Por último, en México, la conmemoración de los quinientos años del aniversario del nacimiento de Bartolomé de las Casas, en 1992, tuvo lugar bajo los auspicios del obispo local Samuel Ruiz. En resumen, los hechos descritos dan cuenta de la atención que reciben las minorías desde finales de los años setenta, así como de la inserción del indianismo en el movimiento general de su despertar.

\section{REDES DE APOYO INTERNACIONALES}

Sin lugar a dudas, el indigenismo y las agencias internacionales aparecen no sólo fuertemente vinculados a la emergencia de los indianismos sino también imprescindibles para ésta. Debemos además considerar, en dicha emergencia, la extensa red de apoyos internacionales. Destacan en ella las Iglesias, principalmente la Iglesia Católica; los representantes de las ciencias sociales y los juristas que difunden los presupuestos culturalistas; las oficinas especializadas de las Naciones Unidas que fijan los marcos políticos y jurídicos, utilizados como instrumentos de legitimación de las pretensiones indígenas; las grandes agencias internacionales (como el Banco Mundial y la Unión Europea) o nacionales que conceden ayudas de acuerdo a criterios étnicos; y las ongs especializadas en temas de medioambiente y desarrollo sostenible, educación y salud. Cabe añadir a esta lista las organizaciones sindicales y politicas de distintas sensibilidades: ecologistas, anarquistas o miembros de la nebulosa altermundialista. Estos diversos conjuntos de redes internacionales están a menudo conectados entre sí, pues muchas de las ONGs en las cuales trabajan también especialistas de las ciencias sociales son, por ejemplo, financiadas por la Iglesia Católica.

La Iglesia Católica, que siempre había querido ser el cimiento de la nación en América Latina, adopta en efecto una nueva política tras el Concilio Vaticano II (1962-1965) "de enculturación (inculturation) de la fe que permite a las comunidades culturales apropiarse el mensaje evangélico" (Favre, 1996: 117). Se podrían multiplicar los ejemplos de las contribuciones materiales e intelectuales de la Iglesia respecto de la fundación y desarrollo de organizaciones indianistas en los últimos veinticinco años, pero basta con decir que estuvo presente en la 
construcción de varias de las organizaciones indígenas citadas hasta el momento, como la Federación de los centros shuars y ecuarunari en Ecuador, el Katarismo en Bolivia, la Unión de las Naciones Indígenas (UNI) en Brasil y el zapatismo en México. La tercera conferencia del episcopado latinoamericano -llevada a cabo en Puebla, México, en 1979- declara al respecto que "la evangelización debe respetar las culturas indígenas y contribuir a la expansión de sus valores" (Favre, 1996: 117). Según el Papa, esta defensa no es solamente un derecho. Se trata de un deber, ya que estos valores se oponen y forman una barrera al materialismo y al individualismo, los cuales, nos atreveríamos a decir, son "conducidos por el neoliberalismo occidental". Tanto es así que, según la fórmula de Sylvie Koller, "el indio, hortelano del mundo, no es solamente un 'buen indio' para la Iglesia, sino que también es un ejemplo para la humanidad en peligro" (Koller, 1994: 222). Bajo el pontificado de Juan Pablo II, la Iglesia Católica, preocupada de luchar contra el comunismo, se empeñó en deshacer las redes inspiradas por la teología de la liberación, demasiado marcadas para su gusto por el marxismo, redes en las cuales algunos zelotes se encontraban, de hecho, vinculados a organizaciones marxistas. Esto es especialmente claro en los años ochenta: el viaje del Papa a Managua ilustra con claridad esta voluntad. Es así como la preferencia por los pobres y su defensa - predicada desde el Concilio Vaticano II- tomará la forma de una exaltación de las culturas nativas y del comunitarismo. Pero, la Iglesia Católica no se encuentra sola en esta lucha. En efecto, el Consejo de Iglesias organizó el primer encuentro latinoamericano de dirigentes indianistas en Barbados, en 1977, dando con ello un impulso clave al movimiento internacional por la defensa de los derechos de los indígenas.

En esta expansión del indianismo, algunos científicos sociales son también protagonistas de primer plano, tanto por sus actos como por las ideas que difunden (Ibarra, 2003), actuando tanto a favor como dentro de los movimientos indígenas, a menudo como asesores y, a veces, como actores muy implicados en su creación, organización y funcionamiento. Ya sea que no pertenezcan al grupo indio al cual la organización dice representar o, cada vez más frecuentemente, que sí provengan del mismo, estos investigadores juegan con su posición social y utilizan sus conocimientos científicos para favorecer la lucha indianista tanto a nivel nacional como internacional. Por ejemplo, el antropólogo estadounidense Richard Chase Smith, da detalles sobre la forma en que sirvió de enlace para un encuentro que tuvo lugar, en 1986, entre la Coordinadora de las Organizaciones Indigenas de la Cuenca Amazónica (COICA) y el Presidente del Banco Mundial (Chase Smith, 2002). Explica cómo aprovechó sus amistades personales y el hecho de que el Presidente "y sobre todo su esposa, simpatizaban con los pueblos indígenas del mundo y con su situación precaria" (Chase Smith, 2002: 225). Este encuentro dio a la Coordinadora, según Richard Chase Smith, "una nueva gama de posibles estrategias políticas para presionar a sus propios gobiernos como también una nueva aura de legitimidad en los círculos oficiales" (Chase Smith, 2002: 207). Se puede medir, entonces, el papel fundamental que tuvieron y que tienen todavía estos mediadores particulares en la historia de los indígenas de América, 
siendo en su mayoría mediadores muy favorables también a la liberación y a la promoción de los pueblos indígenas. Insisten, en general, en el respeto de sus formas comunitarias que se esfuerzan por describir, pero también resucitar, reconstruir o recrear. Es así como el enfoque medioambiental, por ejemplo, promueve la invención de poblaciones etnicizadas para la gestión de recursos naturales, principalmente forestales.

Las Iglesias y los investigadores en ciencias sociales son también la causa del surgimiento de una serie de ONGs. Paralelamente a los movimientos indígenas que se establecen en Norteamérica a finales de los años sesenta, algunos antropólogos fundan en los Estados Unidos el International Work Group Indigenous Affairs (IGWIA) o Survival Internacional (SI), ONGs destinadas a ejercer presión sobre los Estados occidentales para que inciten a la ONU a defender los derechos de las poblaciones locales. Dicho objetivo se alcanza a partir de 1971 (Morin, Santana, 2002). Alison Brysk, profesora de la Universidad de California, proporciona en sus escritos numerosos ejemplos sobre los vínculos entre ONGs y agrupaciones u organizaciones indígenas (Brysk, 1996). Estos vínculos representan en realidad la norma general, puesto que son excepcionales los casos de agrupaciones indianistas desligadas de las ONGs, aunque sus relaciones no se desarrollan sin conflictos. Como lo ejemplifica Brysk, "en 1992, un encuentro destinado a evaluar la condición de los indígenas Huaorani de Ecuador recurrió a representantes de trece ONGs y tuvo en cuenta los briefs de otras quince" (Brysk, 1996: 45). Existen numerosos casos en los que la creación de grupos representativos indígenas es indisociable del trabajo de una o más ONGs. Es también el caso de la Confederación Indigena del Oriente de Bolivia (CIDOB) que estuvo respaldada por la ONG Apoyo Para el Campesinado Indio del Oriente de Bolivia (АРСОВ): fue fundada en 1980 por un grupo de antropólogos, sociólogos y profesionales orientados hacia la investigación-acción con experiencias previas en el Perú, preocupados por defender los derechos territoriales indígenas y por dotarles de un territorio donde puedan reproducir sus prácticas sociales y culturales (Strobele-Gregor, et al., 1994). Para ello, АРСОВ elabora en 1982 un programa interétnico para el cual publica un boletín, financia reuniones, así como viajes nacionales e internacionales (Yashar, 2005). El CIDOB recibe enseguida el apoyo de una serie de ONGs nacionales relevantes, que obtienen fondos de las cooperaciones suiza, holandesa, danesa y alemana, entre otras. Incluso, como lo sostiene Brysk, "es a menudo difícil definir las fronteras tradicionales entre un movimiento social local y sus simpatizantes internacionales". La autora ofrece distintos ejemplos de los que sólo mencionaremos uno: "Cultural Survival y OXFAM América identificaron explícitamente 'la construcción de instituciones' como un objetivo del programa. Y, en un año, Cultural Survival apoyó el desarrollo de las federaciones indígenas nacionales en Brasil, Ecuador y Perú" (Brysk, 1996: 49).

Se podría creer que estos apoyos -o incluso estas creaciones, cuando surge una nueva organización- se orientan solamente hacia los grupos amazónicos, efectivamente dispersos, de menor tamaño, a veces amenazados y, en algunos casos, en peligro de desaparecer. No se trata de vínculos recientes, aunque, indudable- 
mente, la red de apoyos internacionales se enriquece y se densifica a partir de los años ochenta. En Bolivia, el terreno del indianismo nace en primer lugar sobre la meseta andina, en el corazón del gran conjunto campesino de lengua aymará, alentado por algunas ongs de la Iglesia Católica, desde fines de los años sesenta. El Instituto de Investigación Cultural para la Educación Popular (INDICEP), con sede en Oruro, difunde por escrito -pero también gracias a una red de radios- la idea de que la dominación cultural es la base de la frustración, de la alienación y del bloqueo político del mundo quechua-aymará, cuyos valores "de comunión máxima con el cosmos" se oponen a los antivalores de las sociedades materialistas occidentales. Y, en su moderna imprenta offset, el INDICEP imprime y difunde en abundancia los retratos de Tupak Katari y de su esposa Bartolina Sisa, figuras emblemáticas del indianismo naciente a principios de los años setenta.

Tanto los diarios como las radios tienen también un papel importante en la construcción de los movimientos indianistas y en la publicidad que se les hace. Pedro Pitarch, profesor de la Universidad Complutense de Madrid e investigador de la Universidad Autónoma de Chiapas, señala con lujo de detalles cómo el Ejército Zapatista de Liberación Nacional se ha transformado, luego de su intervención armada, en un movimiento indianista, dejando de lado la referencia a Zapata para adoptar la de los indígenas (Pitarch, 2005). Esta transformación se produjo, particularmente, gracias a los artículos del diario La Jornada, redactados por periodistas, pero también por intelectuales mexicanos entre los años 1994 y 1995.

Puede observarse, entonces, cómo las organizaciones o movimientos locales tienen dificultades para sobrevivir si no se inscriben en la línea indianista. Es el caso de los Zapatistas en México, pero también de los sindicatos campesinos bolivianos que compiten, en los llanos, con las agrupaciones étnicas reunidas en la Confederación de Pueblos Indígenas del Oriente Boliviano (СIDOB) y, en el altiplano y en los valles bolivianos, con las agrupaciones de ayllus y las etnias del Consejo Nacional de Ayllus y Markas del Kullasuyo (CONAMAQ).

\section{El reconocimiento del pluriculturalismo}

Se podría plantear, al contrario de lo que se suele pensar a menudo, que el reconocimiento del pluriculturalismo y la multietnicidad favoreció el desarrollo de los movimientos indianistas y que, por lo tanto, no son una consecuencia de éste.

Recordemos los hechos. En la primera conferencia internacional sobre los pueblos autóctonos -organizada por la ONU en 1977- los participantes exigieron la revisión del Convenio 107 sobre las Poblaciones Indígenas, Tribales y Semitribales elaborado por la OIT en 1957. Éste fue transformado, en 1989, en el Convenio 169 relativo "a los Pueblos Indígenas y Tribales en los Países Independientes". Como resultado de dicha transformación, ya no se habla de "asimilación", sino de "pluralismo". Esta mención aparece también en las modificaciones introducidas a las constituciones nacionales de los países de América Latina que ratificaron el convenio. De hecho, la mayoría de los países latinoamericanos añadió o enmendó un artículo 
de su constitución para reconocer la presencia indígena en los años noventa. En México, en 1992 - año de conmemoración del encuentro entre los españoles y las poblaciones precolombinas-, un nuevo párrafo completa el artículo 4 de la Constitución Política de los Estados Unidos Mexicanos. Ahí se afirma que "la Nación mexicana tiene una composición pluricultural basada originalmente en sus pueblos indígenas. La ley protegerá y favorecerá el desarrollo de sus lenguas, culturas, usos, costumbres, recursos y formas específicas de organización social". El carácter pluriétnico y pluricultural del Estado también es reconocido en las constituciones de Colombia (1991), Paraguay (1992), Perú (1993), Bolivia (1994) y Ecuador (1998). Algunas disposiciones que iban en el mismo sentido se habían adoptado previamente en Guatemala, Nicaragua y Brasil. Esta formulación general favorece el reconocimiento de derechos específicos de los indígenas: no sólo condujo a la concesión simbólica de un lugar más digno para las poblaciones indígenas, sino que se materializó en derechos culturales, como el uso oficial de las lenguas indígenas y la instauración de programas y reformas educativas bilingües, financiados en su mayoría por la comunidad internacional. Esta preocupación suena paradójica, puesto que estas mismas lenguas son habladas cada vez menos por las generaciones jóvenes, sobre todo cuando éstas residen lejos de sus regiones de origen.

El reconocimiento de estos derechos culturales fue seguido por la adjudicación de territorios en propiedad-legalizados de manera colectiva- a las poblaciones selváticas, tomando en cuenta la particularidad de su economía basada en la caza y la recolección dentro de ecosistemas específicos. Finalmente, a estos derechos se añadieron formas de autonomía jurídica y política, así como asignación de territorios colectivos en beneficio de poblaciones rurales de los valles y de las mesetas andinas. Tengamos en cuenta que el reconocimiento territorial se hace muchas veces a través de la creación de municipios, esto es, a nivel de la entidad más homogénea posible y, en consecuencia, de la unidad administrativa más pequeña, como se ve actualmente en México y Chile. No obstante, los estudios demográficos dan cuenta de una dinámica de poblamiento opuesta. Se observa, en efecto, una redistribución de la población "de origen indígena" en los territorios nacionales (en las ciudades de México, o en los llanos en el caso de las poblaciones andinas) e incluso fuera de los territorios nacionales (en los Estados Unidos, en particular, para el caso de los indígenas de México). Hasta cierto punto, esta redistribución o dispersión parecen contradictorias con las pretensiones territoriales de las organizaciones indígenas y con la creación de municipios indígenas.

Sin embargo, estas contradicciones no detienen el avance en materia de derechos culturales para las poblaciones indígenas. En México, desde 1995, el Estado Federal de Oaxaca concede a los habitantes de los municipios el derecho de elegir a sus autoridades según dos procedimientos: ya sea mediante el voto individual en favor de candidatos que se reclaman de los partidos políticos (práctica habitual de la democracia electoral) o bien mediante la deliberación colectiva, que conduce a la designación de un candidato único (práctica común según los usos y costumbres de la democracia directa). Este reconocimiento implica nuevas decisiones y nuevas preguntas, como el por qué los habitantes de regiones aparen- 
temente homogéneas optan por un régimen u otro, adhiriéndose, por lo tanto, a una indianidad más o menos afirmada. Según los análisis disponibles, es la historia de las relaciones sociales, económicas y culturales de cada municipio, así como la interacción entre los actores locales las que incitan a hacer una elección u otra (Sonnleitner, Velásquez, 2002).

La auto-administración de la justicia por parte de las comunidades indígenas, de acuerdo a normas comunitarias más o menos codificadas y antiguas, se admite ahora en ocho países: Bolivia, Colombia, Costa Rica, Ecuador, Guatemala, Nicaragua, Paraguay y Perú, así como en algunos Estados de México. En realidad, la novedad reside menos en la práctica misma de esta justicia local de parte de poblaciones que en la mayoría de los casos no tenían acceso a la justicia estatal, carente de recursos, que en el reconocimiento público del pluralismo jurídico. Sin embargo, la articulación con los sistemas jurídicos nacionales es problemática, puesto que algunas penas -como los castigos corporales o los trabajos forzados, el destierro, ostracismo o, incluso, la pena de muerte- van en contra de los principios constitucionales y de los principios universales de los derechos humanos, inscritos en los convenios internacionales ratificados por la mayoría de los países de la región. Y, por supuesto, se plantea también la cuestión de los límites geográficos y sociales dentro de los cuales se ejerce esta justicia, y la posibilidad de apelar los juicios (Van Cott, 2000). Todo ello, sin mencionar la explotación mediática y política de diversos hechos dramáticos como los recientes asesinatos de alcaldes de municipios de las mesetas andinas en Perú (Ilave) y en Bolivia (Ayo Ayo), actos que fueron amparados en la justicia comunitaria, por parte de aquellos que pretendían eludir la responsabilidad del crimen. Para los promotores de esta forma de justicia "democrática", por el contrario, el castigo máximo previsto por ella sería el destierro y en ningún caso el asesinato ${ }^{5}$.

Desde el punto de vista de la autonomía administrativa, Bolivia dio un paso significativo con el voto de la Ley de Participación popular (1994), que crea une nueva categoría jurídica: las Organizaciones Territoriales de Base (OTB). Dicha categoría incluye a las comunidades indígenas rurales de los Andes y a los pueblos indígenas de las Tierras Bajas. Se les concede el derecho de designar representantes -según sus usos- para conformar Comités de vigilancia municipales encargados de proponer proyectos de adaptación y desarrollo a los municipios y, a la vez, de velar por su puesta en práctica. Por otra parte, algunos dispositivos de esta ley prevén tanto la creación de distritos indígenas en el seno de los municipios, como la posibilidad de creación de municipios o de agrupaciones de municipios indígenas.

El Gobierno boliviano inició una nueva etapa en febrero de 2004, al modificar la Constitución, de modo tal que las agrupaciones ciudadanas y los pueblos indígenas reconocidos por la Corte electoral pudieran presentar candidatos a las elecciones nacionales y locales, comenzando por las elecciones municipales de diciembre de 2004. Se trata de una prerrogativa previamente reservada a los par-

La literatura sobre el tema es inmensa. Véase entre otros la crónica moderada de Carlos Soria Galvarro (2004). 
tidos políticos. Ecuador le había precedido en esa vía, desde la reforma electoral de 1995, gracias a una disposición ratificada por la Constitución de 1998. Esta disposición había permitido la creación del Movimiento de Unidad Plurinacional Pachakutik (MUPP), que obtuvo, en 1996, 8 de los 82 escaños del Congreso. Mientras tanto, en Colombia y Venezuela, se crearon circunscripciones específicas para garantizar una representación indígena en las asambleas nacionales, representación a la que pueden aspirar los indígenas sin pertenecer necesariamente a un partido político, una vez más en virtud a las modificaciones de las Constituciones de 1991 y 1999, respectivamente.

En cuanto a la repartición de las tierras, en el caso de Bolivia, la adjudicación de tierras colectivas a los campesinos de las Tierras Altas se acelera. Actualmente, algunas organizaciones campesinas, apoyadas por ONGs como OXFAM, ejercen una fuerte presión sobre el gobierno, exigiendo la incorporación de los recursos del subsuelo dentro del derecho territorial.

En realidad, la situación que se genera es extremadamente variable según los países y depende de al menos dos factores claves. Por una parte, de la importancia numérica de las poblaciones que están en condiciones de pretender a un reconocimiento como autóctonos o nativos, y de la relación con la población global del país en cuestión, pues es evidente que la situación de Brasil o de Colombia dista mucho de la de México y de Bolivia. Por otra parte, influyen la cohesión, la fuerza y la credibilidad de las instituciones nacionales y, en particular, de aquellas que garantizan las funciones regias del Estado como la defensa, el mantenimiento del orden, las finanzas y la justicia.

En efecto, es interesante destacar las contrastadas situaciones nacionales al respecto. En el caso de Brasil, Bruce Albert, antropólogo del IRD-Instituto Socioambiental de São Paolo, constata que después de una fase "de efervescencia política e identitaria", se llegó "a una etnicidad de rutina". Añade que "a una etnicidad política" sucedió una "etnicidad gestionaria [...] muy influida por la retórica del desarrollo sostenible" (Albert, 2004: 69). Sin embargo, en Bolivia se produce una situación inversa: la mezcla, o más bien la agregación de distintas reivindicaciones, condujo a una etnicización de los grupos que pueblan el territorio nacional, generando hostilidades mutuas y escaladas xenófobas, situación que se torna explosiva y que podría incluso provocar a largo plazo una balcanización del país.

\section{El discurso indianista}

La ayuda internacional y el reconocimiento del pluriculturalismo han ido de la mano del discurso sobre las poblaciones indígenas, el cual ha evolucionado durante el último cuarto de siglo. El discurso indianista actual está también vinculado al discurso indigenista, cuestionado en los años setenta por intelectuales ${ }^{6}$

6 En México, ha sido cuestionado sobre todo por los empleados de la institución indigenista del país, antropólogos y promotores. 
y organizaciones indígenas. En ese entonces se representaba al indígena como un trabajador explotado por el capitalismo y la burguesía; pero a quien era necesario guiar hacia la modernidad y asimilar a una nación mestiza. A mediados de los años ochenta, y más aún en los años noventa, esta imagen del indígena volvió a cambiar, convirtiéndose el indianismo en un discurso de "resistencia cultural" a disposición de los intermediarios y políticos indígenas (De la Peña, 1995). En Bolivia, se redactó en 1973 -en plena dictadura militar- un manifiesto difundido ampliamente en el subcontinente y, luego, en todo el mundo: el Manifiesto de Tiahuanaku ${ }^{7}$. En el mismo sentido, en México, a finales de los años ochenta, "varias organizaciones regionales que se definen como representantes de las colectividades indígenas mexicanas, que llaman etnias, pueblos o naciones" reivindicaron el reconocimiento de la presencia indígena por parte del Estado (De la Peña, 1995: 118).

El discurso indianista se escucha también en boca de los representantes electos en las unidades administrativas pequeñas (municipios en México, comunidades agrarias en el Perú) o, bien, entre los indígenas que ocupan en número creciente los parlamentos regionales y nacionales de varios países de América Latina (México, Colombia, Ecuador y Bolivia a partir de 1978). Se oye de igual forma en boca de los líderes de una miríada de organizaciones etiquetadas como indígenas, que actúan en el marco de las fronteras nacionales -y más allá de ellas- en luchas corporativistas o federadoras, casi siempre en un marco legal, aunque a veces recurriendo a la violencia armada. Finalmente, encontramos el mismo discurso en boca de sociólogos o antropólogos, periodistas, políticos y algunos dirigentes de nuevos movimientos sociales latinoamericanos, norteamericanos o europeos.

Actualmente, este discurso encierra todos los temas y emblemas del nacionalismo, con tonalidades más o menos radicales según el contexto nacional y las características de los grupos promotores: designación de los antepasados y de sus grandes hazañas, fabricación de una lengua nacional (o por lo menos su revisión), elaboración de un relato nacional (grandes batallas, encarnación de un ingenio nacional en el mundo rural que mantiene una relación íntima con la tierra), banderas e himnos (Thiesse, 1999). De simples solicitudes pacíficas de reconocimiento cultural de "naciones" -tal como la "nación Zapoteca" en México-, se pasa a reivindicaciones extremas de autonomía de territorios libres de toda presencia occidental o blanca. Así, en Bolivia, Felipe Quispe, el jefe del Movimiento Indio Pachacuti (MIP) afirma: "Vemos en el MIP el instrumento político ideológico de otro Estado, de la nación Qullasuyana. Nosotros no po-

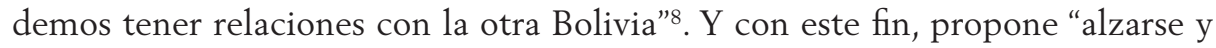
tomar las armas, ejecutar a los patronos y a los traidores (llunk'us) ${ }^{9}$ de nuestras

Uno de los apartados de este documento se titula "Nuestra cultura como primer valor".

Entrevista a Felipe Quispe. 2001. "Preparando la revolución indígena en Bolivia" www.nodo50.org/pretextos/bolivial.html

9 Literalmente, los tapones que flotan. 
comunidades, quemar las casas de los ricos, arrasar y generar hambrunas en las ciudades que nos oprimen y nos explotan"10.

\section{ECOLOGÍA Y ALTERMUNDIALISMO: DOS TEMAS EN BOGA}

Se observan, sin embargo, algunas evoluciones de lenguaje que, al relacionar dicho nacionalismo con temáticas en boga, dan o pueden dar una sensación de novedad. Pero el conjunto de temáticas de los grupos indianistas contemporáneos -la defensa de la identidad (lengua), el ecosistema (medio ambiente), la religión (espiritualidad), la soberanía (territorio, auto-administración, respeto de los usos y costumbres en materia jurídica) - ya estaban presentes en los manifiestos de los indígenas de Estados Unidos en los años setenta. El individualismo, el materialismo, el economismo occidental eran entonces fustigados, a favor de un espiritualismo fundado en el culto a la tierra madre y de un comunitarismo integrador. Al mismo tiempo, el ensayista boliviano Fausto Reinaga, fuente de inspiración de los dirigentes indianistas de los países andinos, escribía: "Somos indios. Una gran raza, raza virgen; una gran cultura, cultura milenaria; un gran pueblo, una gran Nación... El problema del Indio no es asunto de asimilación o de integración a la sociedad blanca, civilizada; el problema del Indio es un problema de liberación" (Reinaga, 1969: 67). Siguiendo en la misma línea, planteaba su concepción de una armonía cósmica entre los principios comunitarios y la naturaleza (Reinaga, 1972).

Hoy en día, dos temas predominan. El primero de ellos es el de la ecología, que se generalizó desde los años setenta y que corresponde a una colusión entre un tema vigente, que moviliza a los ciudadanos de los países occidentales, y situaciones realmente graves, como la de los habitantes de las Amazonas, donde las empresas mineras y petrolíferas, así como colonos de todo tipo (buscadores de oro, silvicultores, ganaderos...) invaden, devastan y contaminan extensas regiones con toda impunidad.

Muchos proyectos creativos puestos en práctica por las organizaciones indígenas para defender sus territorios amenazados o invadidos pretenden obtener el apoyo de grupos occidentales. Tales organizaciones denotan por lo demás tener un buen conocimiento de los gustos occidentales sobre este tema; es el caso, en el Ecuador, de la Red de las comunidades kichwas de Amazonia y Sacha Mama Allpa, que invita a voluntarios internacionales a compartir la vida de los campesinos (Pérez, 2004). Frecuentemente, líderes indigenas recorren Europa y los Estados Unidos para exponer los daños ecológicos que padecen pueblos o regiones enteras. Por ejemplo, en un diario suizo, se publicó una entrevista a un representante indígena, en la cual se le presenta como "un embajador del pueblo kichwa [que] recorre Europa para alertar contra los perjuicios que genera la fiebre del petróleo..."11. En los Estados Unidos, los líderes de la CONAIE (Confederación de las 
Nacionalidades Indígenas de Ecuador) hicieron un extenso recorrido llegando a una audiencia cada vez más amplia (Van Cott, 2003). Incluso, se puede legítimamente pensar que dicha audiencia participó también en el desarrollo de este movimiento que, si bien fue marginal a principios de los noventa, se convirtió en un protagonista político nacional de importancia a partir de 1994 (Selverston-Scher, 2001). Este discurso ecológico, en particular cuando es retomado por algunos simpatizantes occidentales, hace a menudo del indígena el natural conservador de una naturaleza virgen, en oposición con un mundo occidental contaminante y mortífero, portador de un progreso hasta cierto punto regresivo. Los indígenas, por tanto, lejos de ser los representantes de tribus retrasadas (como querían los darwinistas sociales) son o serían los depositarios de un conocimiento perdido que hace o haría de ellos los portadores de un futuro limpio ${ }^{12}$.

Además de la ecología, existe un segundo tema presente en el discurso de los grupos indianistas, que encuentra sus raíces tanto en la corriente autogestionaria como tercermundista, y que ha evolucionado actualmente hacia el anti o el altermundialismo. Por un lado, este tema toma prestada de la primera corriente la idea de que el buen gobierno se hace a nivel de pequeñas unidades de producción o territoriales, donde las decisiones se toman de manera conjunta y consensuada, tras debates en los cuales todos participan (comunidades indígenas, ayllus...). Por otro lado, toma prestada de los altermundialistas la retórica de la opresión, de la explotación capitalista, considerada como una simple prolongación -o incluso presencia- del colonialismo, del cual los pueblos, las naciones o las etnias deberían liberarse. En el lenguaje de hoy, eso equivale a luchar contra la globalización, entendida en su sentido económico de explotación capitalista salvaje y de empresas movidas por lógicas financieras; pero también contra una globalización cultural individualizante, atomizante y, sobre todo, deshumanizante.

En los Andes, una de las últimas movilizaciones internacionales altermundialistas, donde estaban presentes organizaciones indígenas, fue suscitada por la creación del Acuerdo de Libre Comercio de América (ALCA) o Zona de Libre Comercio de América (ZLEA), que comprende a todos los países americanos, a excepción de Cuba, y que debía negociarse a principios de 2005, para entrar en vigencia a finales de ese año. Esta movilización es presentada "como la continuación de la lucha contra el modelo neoliberal iniciada a principios de los años noventa", pero "que no se auto-designa explícitamente altermundialista", según los términos de la politóloga francesa Julie Massal (Massal, 2003: 2). Ésta señala, igualmente, que desde mediados de los años noventa, varias asociaciones de barrios, sindicatos, organizaciones ecologistas, religiosas o del medio universitario, trabajan junto a las organizaciones indígenas en su movilización contra el ALCA (Massal, 2003).

12 Véanse los textos de R. Jaulin, R. Renaud y de los de diversos grupos indígenas difundidos en Francia mensualmente por la América indígena, editado por la asociación Difusión Inti a inicios de los años ochenta, o el Comité de información con el apoyo de los Indios de América (ISIA), creado en Nantes en 1977. 
En el caso de Bolivia, el problema de la propiedad, explotación y comercialización del gas por grandes grupos petroleros ha servido para cohesionar a este mismo tipo de organizaciones. En octubre de 2003, se logró, con sectores indianistas a la cabeza, la renuncia del Presidente Gonzalo Sánchez de Lozada. En ese momento, uno de los estribillos más audaces decía: "el gas nos pertenece por derecho, recuperarlo e industrializarlo es un deber" (Suárez, 2003: 5).

Cabe señalar, además, que si bien el discurso indianista sirve para legitimar una acción, y darle eventualmente un carácter homogéneo y local, éste incluye, a la vez, una extrema variedad de protagonistas que actúan en diferentes niveles. En efecto, los actores indígenas se encuentran en todos los niveles de la escala social, a causa de la categorización del indígena como miembro de culturas indias y de la valoración positiva de éstas por parte de la comunidad internacional, lo cual también influye en su valoración por parte de sectores cada vez más crecientes de las poblaciones locales. Aunque la mayoría de los que son identificados como indígenas por las poblaciones locales y/o que se identifican como tales se ubican en el nivel más bajo de la escala de dominación, otros ocupan, en cambio, lugares intermedios (maestros rurales, empleados, comerciantes o ediles), e incluso posiciones importantes: tal es el caso de dirigentes sindicales o líderes políticos departamentales o nacionales, de altos funcionarios, o incluso de ministros (sobre todo en Ecuador y Bolivia). Asimismo, se encuentran indígenas dispersos en todos los niveles de la escala de educación: desde el analfabeto hasta el que obtuvo un diploma en una universidad nacional o extranjera.

Esta extrema variedad de posiciones intelectuales y sociales permite a algunos de ellos -según los casos y de forma muy desigual- desarrollar verdaderos juegos estratégicos de identificación, los cuales varían según el contexto y el interlocutor. Por ejemplo, algunos se muestran como indígenas orgullosos de sus costumbres, usos y tradiciones ante el movimiento altermundialista o frente a los organismos internacionales de los que pretenden obtener apoyo o créditos; pero, acto seguido, pueden mostrarse despreciativos frente a quienes se dicen sus representantes, esta vez en nombre de su saber intelectual o técnico, o simplemente sirviéndose de su posición social superior y de los poderes que aquella les procura.

\section{LA COERCIÓN COMUNITARIA}

Además, los discursos y las prácticas no siempre coinciden, en particular en los países donde los indianistas ya pesan mucho en la vida política, como en Bolivia o Ecuador. Se observa que los simpatizantes de grupos sindicales, partidos y movimientos indianistas rara vez se plantean preguntas sobre su funcionamiento interno, los mecanismos de designación de sus representantes y el modo de gobierno entre sus filas y en sus territorios. Prefieren presentarse como un útil contrapeso a la globalización neoliberal.

Resulta tanto más fácil cuanto que simbolizan a la vez la lucha de los pequenos contra los grandes -David contra Goliat-, de los humillados y expoliados 
contra los acaparadores, o también de los colonizados contra los colonizadores, de los "buenos salvajes" contra los invasores pervertidos. No obstante, una mirada más cercana sobre algunas prácticas y ciertas lógicas de funcionamiento internas debería inducir otras reflexiones sobre la democracia de dichos movimientos, más allá de aquellas que habitualmente se proporcionan cuando se presenta su reconocimiento como un avance democrático por el simple hecho de que, por fin, se ha dado un lugar a las etnias o naciones indígenas dentro de las constituciones y las leyes.

En Bolivia, trátese de organizaciones de cocaleros, de organizaciones campesinas del altiplano, o de los gremios (comerciantes del mercado y la calle, transportistas, etc.), todas funcionan en base al método de la coerción organizativa. Es necesario pertenecer a ellas para trabajar y no resulta posible escapar de las directrices de los dirigentes. En efecto, disentir se paga muy caro. La coerción que existe en estas organizaciones politicas es igualmente fuerte en muchas comunidades indígenas (en Perú o en México), donde cada familia debe participar en los trabajos colectivos de interés público (construcción de escuelas, de carreteras), así como en la financiación de las fiestas religiosas y en el nombramiento de los puestos de responsabilidad administrativa y política; de lo contrario, pesa sobre ella la amenaza de perder su casa, su tierra y ser expulsada del territorio. Respecto a las organizaciones políticas, nos encontramos precisamente en el caso descrito por Mancur Olson acerca de las acciones colectivas que no existirían sino mediante el ejercicio de la coerción. Ello no implica inevitablemente plantear la existencia de un desacuerdo de fondo entre las decisiones de la base o entre las bases y la cúpula, pero sí que la defección tiene un costo que puede ser elevado. En Bolivia, en el Chapare -la principal zona de cultivo de la coca destinada al narcotráfico-, la totalidad de la familia es obligada a participar en los bloqueos de carreteras en la zona en cuestión ya que si no lo hace, se expone a un complejo sistema de multas escalonadas. Tanto es así que los días de bloqueo, los niños no van a la escuela; y, en última instancia, el infractor puede ser desposeído de su tierra. Se podrían multiplicar los ejemplos, pero basta con leer los diarios para descubrirlos.

Los conflictos que han opuesto estas organizaciones a diversas instancias gubernamentales, sobre todo estos últimos años, han incrementado la presión interna en cada uno de los sectores organizados. Los cocaleros llevan adelante una verdadera guerra contra el ejército y la policía y, en consecuencia, los sindicatos locales no pueden tolerar divergencias, las cuales son consideradas inmediatamente como disidencias: es necesario acatar. Lo mismo sucede en la región de Achacachi, dominada por Felipe Quispe, el "Mallku"13, donde todas las autoridades que no se encontraban conformes con su línea política fueron remplazadas. Los cuarteles militares acorralados representan el único símbolo del Estado central que permanece en su lugar, aunque actualmente el Estado ha recuperado un poco de terreno en esta zona. Ocurre lo mismo en determinados sectores ur-

13 Autoridad indígena en territorio de lengua aymará. 
banos, que son también controlados por organizaciones de barrio, como en el caso de casi la totalidad de la ciudad de El Alto, situada en los suburbios de La Paz.

Asimismo, los líderes de las asociaciones de vendedores ambulantes de la ciudad de México utilizan la amenaza y el terror para asegurarse la "lealtad" de sus miembros, según la antropóloga mexicana Cristina Oehmichen (Oehmichen, 2003). Tienen a su servicio un grupo que tranquiliza las disidencias y obliga a entregar "la cotización del terror", que corresponde a la suma que el comerciante paga para ocupar un pedazo de acera o una esquina de la calle, donde disponer su puesto de venta. Este dinero se concentra en manos de los líderes, quienes, como en el caso de las organizaciones no étnicas, según destaca Cristina Oehmichen, se eternizan en sus puestos de dirigentes y mediadores con el Estado, adoptando ciertas prácticas de "caciques" locales.

\section{Las estrategias identitarias indianistas}

En la medida en que se trate de minorías o de poblaciones anteriormente colonizadas -que puedan aún ser consideradas como tales-, los autonomismos o nacionalismos indígenas actuales son generalmente considerados como liberadores y, por lo tanto, inscritos en orientaciones de izquierdas. Se trata de una amalgama heredada de las luchas medioambientales, tercermundistas y autogestionarias de los años setenta, llevadas por distintas izquierdas (que van desde los anarquistas hasta los socialistas), pasando por corrientes marxistas y, por supuesto, ecologistas. Se trata de izquierdas que se pelean entre sí, pero que tienen en común el hecho de encontrar en tal o cual grupo indio el apoyo o el sustento necesario para su discurso.

Ahora bien, por una parte, acabamos de ver que este posicionamiento en el tablero político, así como la situación de dominación de dichas poblaciones, se limita a tomar en cuenta al enemigo figurado -ya sea el ogro capitalista o imperialista o el Occidente nocivo-, pero sin interesarse por los discursos, perspectivas políticas y funcionamiento de estos grupos. Y, por otra parte, la promesa recurrente de estos movimientos de volver a cierto paraíso perdido, acaba ocultando la realidad de sus proyectos políticos.

Como lo señalamos, las preocupaciones ecológicas contemporáneas y las visiones seculares del buen salvaje, se juntan para hacer del indígena el conservador natural de la flora y la fauna. Así, en algunas zonas, en particular las amazónicas, nacieron proyectos de eco o de etno-desarrollo, bajo la forma de programas empresariales financiados, según los casos, por algunas ONGs, por organismos multilaterales o por empresas privadas. A menudo, estos proyectos van de la mano con la concesión de territorios propios a las poblaciones locales, cuya misión consiste en proteger tanto su cultura como la naturaleza. Estos dos aspectos no son disociables en este tipo de lógica, puesto que esta cultura original es considerada como el fundamento de la producción "orgánica" de alimentos, medicamentos, industrias textiles, de caucho... y, por lo tanto, de la conservación de la naturaleza. 
Este tipo de planteamiento, bien intencionado, no está exento de efectos perversos. En primer lugar, parece que estos proyectos florecen en zonas donde el Estado ha abandonado sus responsabilidades respecto a los servicios básicos (educación, salud...) -si es que alguna vez tuvo en ellas alguna implicación, puesto que estas zonas fueron, en muchos casos, tuteladas por las Iglesias-. De esta forma, la misión del Estado fue de cierta manera delegada a prestatarios de servicios externos, cuya continuidad por un lado, pero también cuya misión de servicio público por otro, resultan problemáticas. Además, después de más de dos décadas de experiencias, estos programas presentan resultados muy limitados. Según un reciente artículo del semanal norteamericano Newsweek, esta concepción económica de la protección de la naturaleza no ha permitido frenar la destrucción de los bosques amazónicos, pues la tala selectiva de árboles resulta costosa e ineficaz, las actividades de recolección respetuosas del medio ambiente (cosechas de frutos silvestres, látex, nueces...) no son rentables, "y la demanda insaciable por los medicamentos naturales ha conducido entre 4.000 a 10.000 especies vegetales al borde de la extinción"14. En suma, la pregunta que se plantea a las eco-empresas y a los eco-programas consiste en saber si la protección del medio ambiente puede adaptarse a una actividad comercial. Desde nuestro punto de vista, se comprenderá fácilmente que el aluvión de fondos destinados a estas zonas y a estas poblaciones implica, por una parte, la multiplicación de grupos identitarios indígenas rivales que compiten para acceder a dichos fondos y, por otra parte, las manipulaciones, disputas y conflictos que las acompañan inevitablemente.

En materia identitaria, se asiste generalmente a una dinámica compleja de ajustes, adaptaciones e hibridaciones entre usos y costumbres indígenas y los estereotipos que se les asigna desde afuera. Por otra parte, queda claro que, en la medida de sus posibilidades, estos grupos o sus representantes negocian rudamente los términos de ciertos contratos. Se encontrará un excelente ejemplo de esta "dialéctica compleja" en el análisis que hace Bruce Albert sobre la movilización de los indígenas Kayapo brasileños ("estrellas políticas y mediáticas" de los años noventa), quienes consiguieron, gracias a los apoyos que recibieron, parar la construcción de represas sobre el río Xingu (Albert, 1997). Se ve en particular cómo, durante una reunión mediática, los líderes del grupo articularon el lenguaje de "la etnicidad ecologista" destinada al mundo exterior -militante y mediático, difundido en portugués- con una ceremonia tradicional, un rito colectivo Kayapo, que da sentido al encuentro de los autóctonos en función de su cosmología y su lengua. En este caso, los beneficios del trabajo de movilización realizado no son escasos, puesto que los Kayapo obtuvieron también la legalización de una reserva de propiedades de un millón de hectáreas.

Pero, como lo señala Bruce Albert, si bien estas estrategias de alianzas consiguen evitar lo peor -esto es, la desaparición física del grupo- en tanto dinamizan una reactivación de la iniciativa del grupo y dan muestra de sus capacidades 
estratégicas y adaptativas, también es necesario señalar sus límites. Las iniciativas económicas asumidas por el grupo y sus líderes difícilmente se ajustan al estereotipo del indígena ecologista. Un ejemplo de lo anterior lo podemos advertir en la firma de un contrato con la empresa Bodyshop, la cual utiliza tintes y nuez de Brasil para fabricar productos de belleza. Esta empresa se convirtió en "cliente e inversionista único de los trading companies Kayapo" y así se fabricó "un capital de eco-exotismo publicitario". Pero hoy en día el contrato está roto después de "una áspera pelea sobre la repartición de las royalties"15. Finalmente, la empresa Bodyshop recurrió rápidamente a la producción de grandes plantaciones, cuando la recolección en el bosque se reveló insuficiente.

Este ejemplo muestra con claridad que es necesario desconfiar del doble espejismo siguiente: por una parte, el del indígena naturalmente ecologista y, por otra parte, el de la empresa filantrópica. No hay que confundir la lucha ecologista y el "eco-exotismo publicitario". Dicho de otro modo, la realidad estudiada a lo largo del tiempo permite desenmascarar los estereotipos.

Siempre es conveniente recordar las lecciones de Georges Balandier y Roger Bastide, quienes invitan a alejarse de una etnología "sabrosamente exótica"16, para volver a situar las culturas en su contexto o en su marco social -deberíamos decir volver a los ajustes y las hibridaciones (bricolages) culturales- para salir así de aquella imagen demasiado fija y esquemática que conlleva un culturalismo simplificado. Ahora bien, este marco sigue siendo el de la estratificación, de la competición y del conflicto. Desde la conquista hasta un período reciente, se ha situado siempre a los indígenas en la parte más baja de la escala de dominación y explotación, hasta el punto que el concepto mismo de "indio" sólo tomaba sentido en esta posición social inferior. Tanto durante el período colonial como en el período republicano, un indio que salía de su posición inferior entraba, en los Andes, en la categoría intermedia de "cholos" o "mestizos" (misti) ${ }^{17}$ y, en América Central, directamente a la de "ladino"18.

Este abanico de identificaciones conduce a estrategias políticas que también varían según el contexto y la coyuntura. Si actualmente, el reconocimiento y el apoyo internacional llevan a la creación, al reconocimiento y a la financiación de reagrupaciones y partidos indianistas -como lo comprendió muy pronto el Ejército Zapatista de Liberación Nacional que pasó del discurso marxista al del indianismo (Pitarch, 2005)-, siempre es posible que tal o cual grupo, facción o fracción, se alíe

\footnotetext{
"Les éco-entreprises à 1'heure du bilan”, Courrier international 699, 25-31 marzo 2004.

Georges Balandier, programa en la radio France Info, 2 de mayo de 2004.

Sobre la noción de cholificación, véase Bourricaud (1962).

Término que designa a los que dejaron de ser indigenas en América central y en una parte del sud-este mexicano.
} 
con partidos políticos cuya etiqueta no se encontraba en una pertenencia étnica o cultural. Es lo que muestra la agitada historia del indianismo boliviano desde fines de los años setenta.

Dicho de otro modo, el ejemplo del desarrollo sostenible y de la lucha política ecologista desarrollado más arriba, ilustra bien esta situación de juegos estratégicos adaptativos de parte de grupos indígenas organizados -deberíamos decir más bien grupos indianistas- articulados en redes, si no mundializadas al menos occidentalizadas, en las cuales cada socio trata de obtener ventajas de los demás, en función de los recursos de los que dispone. Sin embargo, los dominantes están siempre del mismo lado. Son, por supuesto, las empresas que venden lo "étnico". Son igualmente los que fabrican las políticas de desarrollo, quienes -debido a la protección selectiva que ofrecen a los pobres y a los amenazados, a quienes ayudan en función de criterios étnicos- dejan de lado a amplios sectores de las poblaciones urbanas, que no se etiquetan suficientemente como indígenas, o que tienen contornos demasiado borrosos, o una "autenticidad" hasta cierto punto dudosa. Son también este tipo de empresas las que apuestan por una clase de renacimiento, o incluso de revolución (económica, política, ecológica...) cuyo "buen salvaje" serviría de modelo y que fomentan, acreditan y autentifican toda expresión de indianidad cultural, cualquiera sea finalmente el mensaje político del cual es portadora y el tipo de organización que la difunda.

\section{Bibliografía}

25-31 mars 2004. "Les éco-entreprises à l'heure du bilan". Courrier international 699.

Albert, BRUCE. 1997. "Territorialité, ethnopolitique et développement: à propos du mouvement indien en Amazonie brésilienne". Cahiers des Amériques latines 23: 205-210.

Albert, Bruce. 2004. "Les Indiens et l'Etat au Brésil". Problèmes d'Amérique Latine 52, primavera 2004: 63-84.

Bourricaud, François. 1962. Changements à Puno. París: Institut des Hautes Etudes de l'Amérique Latine.

BRYSK, Alison. 1996. "Turning weakness into strength. The internationalization of Indian rights". Latin American perspectives 3 (2), primavera 1996: 38-57.

Chase Smith, Richard. 2002. "Los indígenas amazónicos suben al escenario internacional. Reflexiones sobre el accidentado camino recorrido". En Morin, Santana, Lo transnacional. Instrumento y desafío para los pueblos indigenas. Quito: Abya Yala, 203-241.

De la Peña, Guillermo. 1995. "La ciudadanía étnica y la construcción de los indios en el México contemporáneo”. Revista Internacional de Filosofía Politica 6: 116-140.

Favre, Henri. 1996. L'indigénisme. Que sais-je ? París: PUF.

Ibarra, Hernán. 2003. "Neo-indigenismo, indianismo. El caso de Ecuador", http://www. mapuche.info/mapuint/ibarra030600.html.

Koller, Sylvie. Febrero 1994. "Ambigüité dans la défense de l'Indien en Amérique Latine". Etudes 602: 114-130.

MARIEnStras, Elise. 1980. La résistance indienne aux Etats-Unis du $16^{\text {ème }}$ au $20^{\text {ème }}$ siècle. París: Gallimard, Coll. Archives.

Massal, Julie. 2003. "Les Indiens d'Equateur contre la mondialisation? La mobilisation contre la Zone de Libre Echange des Amériques". Ponencia realizada en el coloquio Les mobilisations altermondialistes. París, 3-5 décembre 2003. 
Morin, Françoise; SAntAna, Roberto (comps.). 2002. Lo transnacional. Instrumento y desafio para los pueblos indígenas. Quito: Ediciones Abya-Yala.

OeHMichen, CRISTINA. 2003. "Relaciones interétnicas y discriminación urbana. El caso de las mazahuas en la ciudad de México”. En Bonfil Sánchez, Paloma; Martínez Medrano; Elvia Rosa (coord.). Diagnóstico de la discriminación hacia las mujeres indígenas. México: Comisión Nacional para el Desarrollo de los Pueblos Indígenas, 154-176.

PAZ, OCtAVIO. 1985. Une planète et quatre ou cinq mondes. Réflexions sur l'histoire contemporaine. París: Folio Essais.

Paz, Octavio. 1992. Le labyrinthe de la solitude. París: Gallimard.

Pérez, Benito. 16 de febrero 2004. "Equateur: peuples indigènes et pétrole". Le Courrier (Suiza).

Pitarch, Pedro. 2005. "Los zapatistas y el arte de la ventriloquia". Communisme 83/84.

Reinaga, Fausto. 1969. La revolución india. La Paz: Ediciones PIB.

Reinaga, Fausto. 1972. Ideología y raza en América Latina. La Paz: Ediciones del futuro.

Selverston-Scher, Melina. 2001. Ethnopolitics en Ecuador: Indigenous Rights and the Strengthening of Democracy. Coral Gables, Fla: North-South Center Press.

Sonnleitner, Willibald; Velásquez, María-Cristina. 2002. En Hémond, Aline; Recondo, David (coord.). Dilemas de la democracia en México. Los actores sociales ante la representación politica. México: Institut Fédéral Electoral, Centre Français d'Etudes Mexicaines et Centraméricaines, 123-143.

Soria Galvarro, Carlos. 16 junio 2004. "Linchamiento y justicia comunitaria". La Razón.

Strobele-Gregor, Juliana, et al. 1994. "From Indio to mestizo... to Indio. New indianist movements in Bolivia". Latin American perspectives 21 (2), primavera 1994: 106-123.

SuÁrez, Hugo José. 2003. Una semana fundamental: 10-18 octubre. La Paz: Muela del Diablo.

Thiesse, Anne-Marie. 1999. La création des identités nationales. Europe XVIIIe-XXe siècles. París: Seuil.

Van Cott, Donna Lee. Junio de 2003. "Indigenous struggle". Latin American Research Review 38 (2): 220-233.

Van Cott, Donna Lee. 2000. "A political analysis of legal pluralism in Bolivia and Colombia". Journal of Latin american studies 32: 207-234.

YASHAR, DeBORAH J. 2005. Contesting citizenship: indigenous movements, the state and the postiberal challenge in Latin America, www.princeton.edu/ dyashar/manuscripts.html. 
